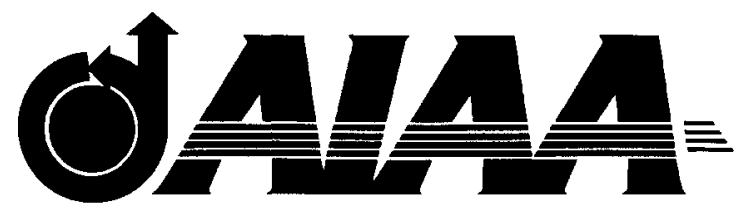

A01-37346

AIAA-2001-4144

\title{
ACTIVE FLOW CONTROL USING HIGH FREQUENCY COMPLIANT STRUCTURES
}

Russell F. Osborn

Sridhar Kota

FlexSys, Inc.

(d.b.a. Mechanical Compliance Inc.)

Brighton, MI

Donald Geister

Michael Lee

University of Michigan

Ann Arbor, MI

Carl P. Tilmann

Air Force Research Laboratory

Air Vehicles Directorate

Wright-Patterson AFB, OH

\section{AIAA Guidance, Navigation, and Control Conference \& Exhibit 6-9 August 2001 / Montréal, Canada}




\title{
ACTIVE FLOW CONTROL USING HIGH FREQUENCY COMPLIANT STRUCTURES
}

\author{
Russell F. Osborn ${ }^{*} \&$ Sridhar Kota ${ }^{\dagger}$ \\ FlexSys, Inc. (d.b.a. Mechanical Compliance Inc.) \\ Brighton, $M I$ \\ Donald Geister ${ }^{\ddagger}$ \& Michael Lee M $^{\S}$ \\ University of Michigan \\ Ann Arbor, $M I$ \\ Carl P. Tilmann ${ }^{* *}$ \\ Air Force Research Laboratory, Air Vehicles Directorate \\ Wright-Patterson $A F B, O H$
}

\begin{abstract}
Flow control to avoid or delay boundary layer separation on a wing can dramatically improve the performance of most air vehicles in strategic parts of their individual flight envelopes. Prior aerodynamic experiments and computations have indicated that unsteady excitation at the appropriate frequency can delay boundary layer separation and wing stall more effectively than steady flow perturbations, and that these unsteady perturbations, when generated in an optimum frequency range, maximize the extent of flow separation control for specific flight conditions. Preliminary aerodynamic experiments have been performed on a deflected trailing edge flap to evaluate turbulent boundary layer separation control with a deployable high frequency micro vortex generator (HiMVG) array. The HiMVG design tested incorporated emerging displacement amplification compliant structures technology that deployed micro vortex generator blades $5 \mathrm{~mm}$, through a range of frequencies between 30 and $70 \mathrm{~Hz}$, when driven by an appropriately sized voice-coil actuator. The mechanical high frequency micro vortex generator system tested produced an oscillatory stream of boundary layer embedded vortices that proved effective in mitigating flow separation on the upper surface of a deflected flap when a similar array of static vortex generators could not. A second generation HiMVG design driven by a piezoelectric actuator was also conceptualized. Candidate flow control applications for this second generation design are discussed.
\end{abstract}

\section{Introduction}

Flow separation control using unsteady perturbations is not entirely new, in fact there have been several recently funded projects in this area ${ }^{1,2,3}$ addressing pneumatic concepts that have produced some rather exciting results. For example, the pulsed vortex generator jet work, initiated by McManus $^{2}$ is proceeding on two fronts, one studying dynamic stall improvement ${ }^{4}$, and the another focused on

\footnotetext{
"Senior Research Engineer, Senior Member AIAA.

+ President.

$\ddagger$ Research Scientist and Lecturer, Member AIAA.

$\$$ Research Assistant, Member AIAA.

** Research Aerospace Engineer, Senior Member AIAA.
}

reducing shock induced separation on transonic airfoils ${ }^{5}$. The thrust of the work reported in this paper, on the other hand, details the initial development and testing of an unsteady flow control device that is an electrically operated mechanical design. The overarching project goal has been the development and demonstration of an oscillatory flow control device that performs the flow control function as well as the best pneumatic systems. However, because of design simplicity, this type of device may be

Copyright $\subset 2001$ by the American Institute of Aeronautics and 1
Astronautics, Inc. All rights reserved. 


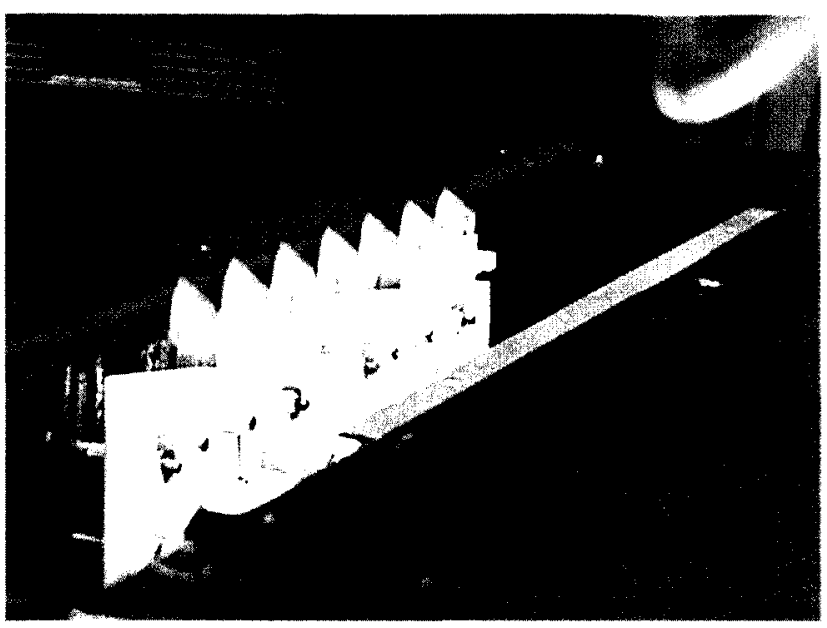

Figure 1: High Frequency, Deployable Micro Vortex Generator System

easier to integrate; particularly for transonic flow control applications where the mass flow requirements of pneumatic systems can be significant.

The flow control mechanism of the referenced pneumatic systems is to generate periodic vortices in a separating flow at or near an optimum frequency. Vortices formed at this frequency exhibit high streamwise momentum and are driven toward the surface energizing the boundary layer thus eliminating massive separation. While the pneumatic systems produce their unsteady flow excitation by injecting air in an oscillatory manner, the high frequency micro vortex generator (HiMVG) device presented here produces its unsteady flow field by moving a mechanical element (in this case a micro vortex generator) at the optimum frequency for the flow conditions involved. The mechanical system illustrated in Figure 1 uses a 20:1 displacement amplification compliant structures device designed by Kota, that when driven by an actuator with the proper characteristics, can deploy a blade vortex array to the height required for effective vortex formation.

The aerodynamic device used to produce the oscillatory flowfield, the micro vortex generator, was configured according to the design parameters developed by $\operatorname{Lin}^{6}$ in his benchmark research on vortex generator size optimization for turbulent boundary layer separation control. A prior attempt at using deployable vortex generators for boundary layer separation control $^{7}$ had system design constraints that has thus far limited deployment frequency to the $10-20 \mathrm{~Hz}$ range. This system performed the separation control function as well as a static vortex generator array, but operated at a reduced frequency well below that needed for optimum separation control based on prior experimental evidence. A properly designed displacement amplification compliant structure, coupled with an appropriate actuator, eliminates this vortex generator deployment frequency constraint. Compliant structure technology permits the design of a mechanical system that can generate an oscillatory flowfield at the reduced frequency needed for best separation control performance.

\section{Boundary Layer Separation Control}

Many boundary layer separation control concepts have been studied in prior research efforts, and developed to varying degrees. Several of the more recent dynamic flow control concepts that are pertinent to this research activity will be discussed in some detail. But first, details of a static flow control concept with relevance to this project will be reviewed.

The vortex generator, or more specific in its relationship to this dynamic flow control project, the micro vortex generator, a compact version of the larger boundary layer height $(\delta$ scale) vortex generator developed and patented by Taylor of United Aircraft Corporation, dates back to 1947. Lin's recent research ${ }^{6}$ on reducing the size of vortex generators, while still retaining their boundary layer control performance, led to the development of what he called a micro vortex generator, with a blade height of from $0.2-0.4$ times the boundary layer thickness, that proved just as effective in preventing the separation of a turbulent boundary layer as the larger $\delta$-scale VG's with a considerable reduction in total system drag. 
While drag is not a critical issue with deployable vortex generators, which are only inserted into the flow when required, the need to rapidly deploy the devices at the high frequencies required to produce good dynamic flow control results requires a small, light weight vortex generator blade. Therefore, he Lin optimized blade shapes are compatible with the HiMVG design philosophy.

Vortex generators work by increasing the mixing between high-energy air in the outer regions of the boundary layer with the low energy air near the surface. This mixing is accomplished by an appropriately sized and oriented blade located on the aerodynamic surface. Vortex generator blades in effect produce a coherent helical vortex structure that moves high momentum air towards the surface energizing the low energy air. An excellent account of this boundary layer mixing process is given, in the classic paper on the subject, by Schubauer \& Spangenberg ${ }^{8}$. Of particular interest to the current research activity is the fact that properly designed vortex generators produce strong, coherent vortex structures that trail downstream. In the dynamic flow control concepts to be discussed next, this factor becomes an important parameter with regard to system performance.

The two active flow control concepts that form the basis for the high frequency micro vortex generator research of this project are the Pulsed
Vortex Generator Jet (PVGJ) concept of McManus $^{2}$ and periodic excitation control studies of Wygnanski ${ }^{9}$. While the exact mechanism of flow control by unsteady excitation is not fully understood, both the referenced concepts involve the formation of vortices in a separating flow. If this periodic formation of vortices occurs at or near an optimum frequency, the transfer of energy from the outer region to the inner region of the boundary layer is maximized. For the two concepts identified above, air is the working medium that produces the unsteady excitation. The concept of this research effort, on the other hand, produces the unsteady excitation by appropriate motion of a mechanical element, a deployable micro vortex generator.

First, background on the PVGJ system developed by McManus and his co-workers. This system uses a jet, pulsing at the correct frequency, to produce a high-energy vortex structure tuned to the boundary layer shedding frequency. The PVGJ system can readily adjust three parameters; the pulsing frequency, jet velocity ratio and duty cycle, to produce the coherent structures that maximize energy addition into the boundary layer preventing separation. Figure 2 shows the separation control potential of the PVGJ concept in a subsonic flow environment. This level of flow control performance is quite dramatic when the pulsing frequency is properly tuned. Also, the
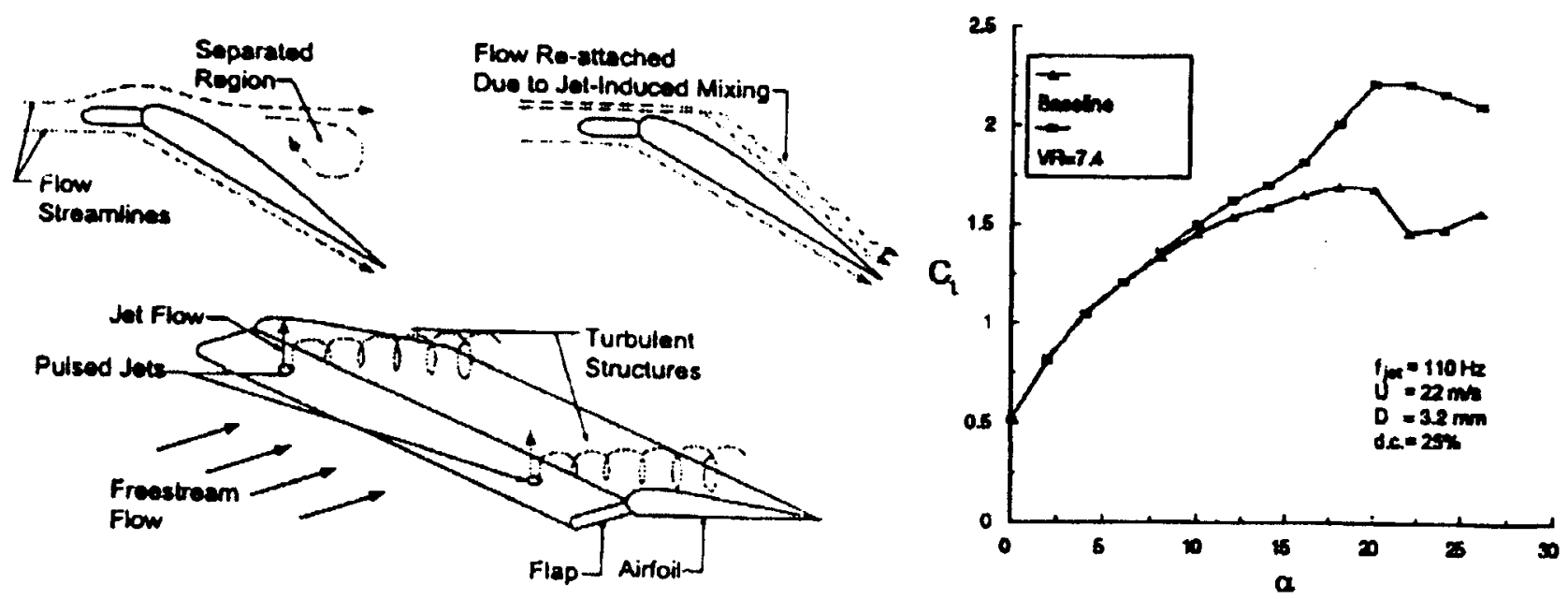

Figure 2: Pulsed Vortex Generator Jet, Subsonic Flow Control (McManus). 


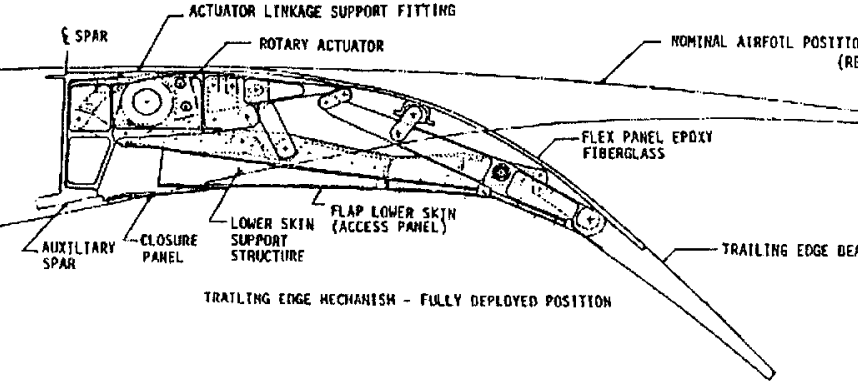

Figure 3: Mechanical (Left) and Compliant (Right) Structure Trailing Edge Flap Designs

mass flow rate required to effect this performance improvement is low for subsonic flow conditions.

However, in a transonic flow environment, the mass flow required to produce coherent vortex structures can become significant. This factor plus integration difficulties have been the major deterrents limiting PVGJ applications.

A series of flow control tests conducted by Wygnanski and his former students (Ref. 1 describes one) has demonstrated flow control results similar to McManus's work using a different excitation process. Wygnanski and his colleagues used a low steady blowing configuration with oscillatory blowing at the "correct" frequency to modulate the formation of vortices. Both McManus and Wygnanski use a Strouhal number based relationship to develop an empirical expression for optimum flow attachment. In this report the Wygnanski form of the empirical relationship is utilized because it is more directly applicable in terms if dimensionality to the aerodynamic testing conducted with the HiMVG system. The expression is:

$$
F^{+}=\frac{f \cdot X_{t e}}{U}
$$

Where:
$F^{+}$reduced frequency (non-dimensional)
$f$ unsteady flow disturbance frequency $(\mathrm{Hz})$
$X_{t e}$ distance from actuator position to trailing edge of wing/flap (ft)
$U$ freestream velocity $(\mathrm{ft} / \mathrm{sec})$

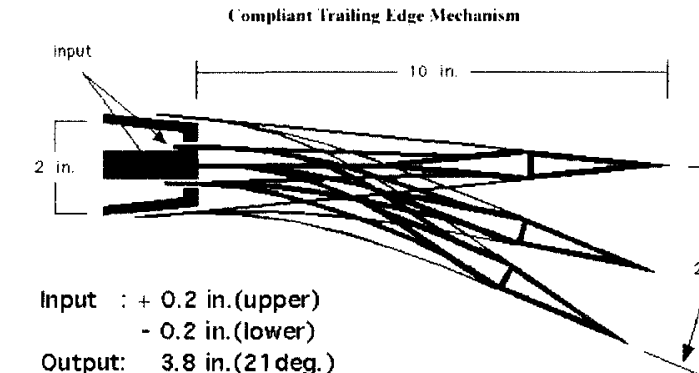

After conducting numerous experiments, Wygnanski and his co-workers documented that optimum flow attachment, at least for subsonic flow on a deflected flap, occurred when $F^{+} \sim 1$. This finding was confirmed by data generated during this program. These results will be discussed in a subsequent section of this paper.

\section{Displacement Amplification Compliant Structures}

A compliant mechanism is a relative new class of mechanism that relies on elastic deformation of its constituent elements to transmit motion and/or force. These are in fact mechanisms without joints - neither conventional hinges nor flexural hinges. The mechanisms have compliance distributed throughout the structure and are much more fatigue resistant and easy to manufacture. Distributed compliant systems derive their flexibility due to the topology and shape of the material continuum rather than concentrated flexion at few regions as in plastic hinges. These novel mechanisms can be readily integrated into air vehicle sub-systems. Figure 3 compares a compliant variable camber flap trailing edge flap designed by Mechanical Compliance Inc. with the multi-component mechanical design developed during the Mission Adaptive Wing program. In this example, it is easy to see the potential weight and durability advantages inherent in a properly designed compliant structure.

In this project, a displacement amplification compliant structure is used as the heart of the HiMVG active flow control system. 


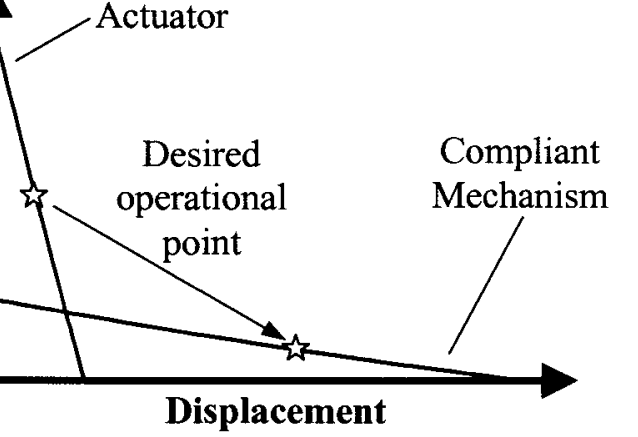

(a) Actuator-'-ailoring using Compliant Mechanisms

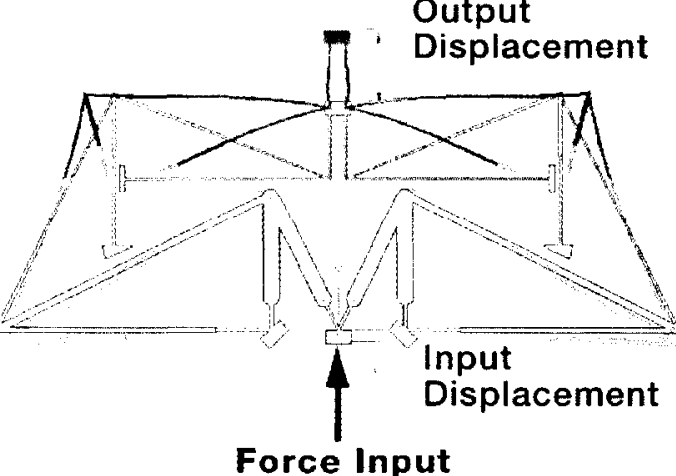

(b) Deformed and Un-deformed Positions of a Compliant Displacement-Amplification Mechanism

Figure 4: Example of a Compliant Displacement-Amplification Mechanism

One of the major barriers in smart structures technology is the displacement, or stroke, available from smart material actuators. Augmenting actuators (such as piezoelectric or voice coil actuators) with compliant mechanisms leads to systems with actuation functionality built into the structure. Such structures distribute the actuation energy derived from an actuator to the application surface. Figure 4 illustrates the type of motion amplification, compliant structure used to drive the high frequency, deployable micro vortex generator. A voice coil motor was used to generate an input force in the correct frequency range. A second generation HiMVG design using a piezoelectric actuator was also designed.

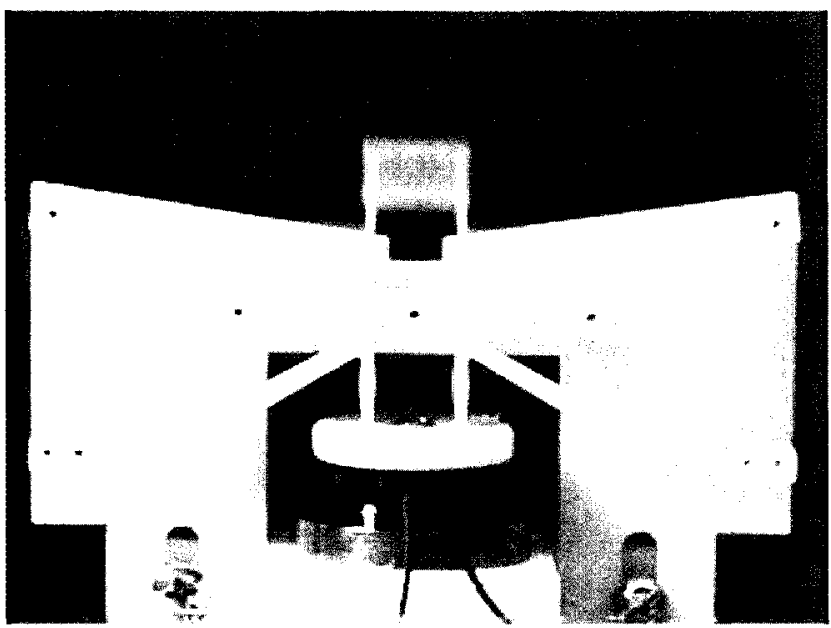

Figure 5: The Actuator-Amplifier Running at $240 \mathrm{~Hz}$ - The Amplified Motion is $5 \mathrm{~mm}$
This device will be described in the future research directions section.

Using compliant structures design tools developed in-house, a displacement amplification compliant structure was designed and optimized for the flow control project. The structure was configured to take the $0.25 \mathrm{~mm}$ output displacement of a BEI Kimco voice-coil actuator with the required frequency range, and amplify the motion to an output of $5 \mathrm{~mm}$, which is the micro vortex generator height required to produce the needed vortex stream for effective dynamic flow control, using the aerodynamic model that will be described in a following section. Details of the displacement amplification, compliant structure design and fabrication process are presented in Reference 10.

The operational compliant structure and actuator are shown during bench testing in Figure 5. As noted the system is capable of producing the required displacement amplification at $240 \mathrm{~Hz}$ deployment frequency.

An indication of the size/frequency versatility of displacement amplification devices is illustrated in Figure 6. This figure shows a MEMS size device capable of operating in the kilohertz frequency range. The compliant structure part of the mechanism was designed by Mechanical Compliance Inc. to produce an output displacement of 20 Microns. 


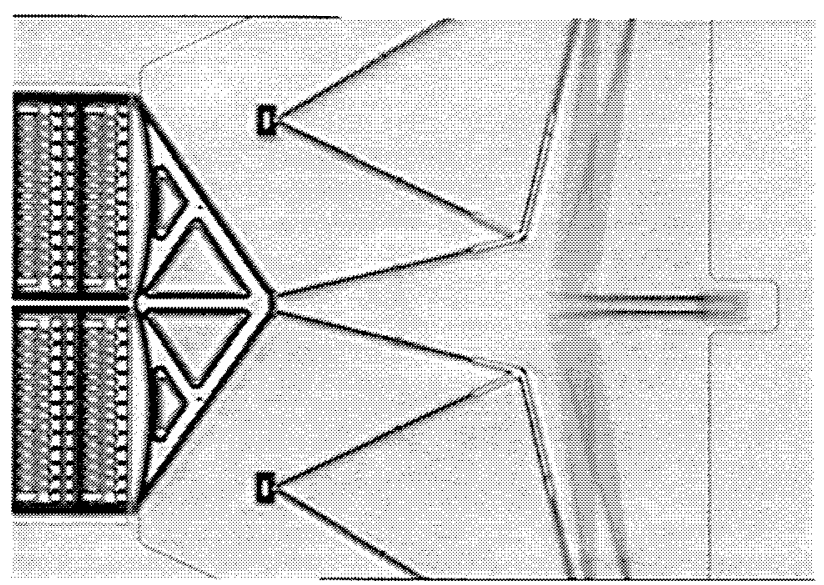

Figure 6: Electro-Static Actuator Driving a Compliant Amplifier at $26.9 \mathrm{KHz}$

\section{High Frequency, Deployable Micro Vortex Generator System}

\section{Vortex Generator Sizing}

A co-rotating vortex generator array was selected for both static and dynamic testing. The individual blade geometry, orientation and spanwise spacing where configured using the relationships developed and validated by $\operatorname{Lin}^{6}$. The flat plate aerodynamic test article, which will be described, was configured to produce a turbulent boundary layer $1 / 2$-inch in height at the vortex generator position located forward of an adverse pressure gradient region produced by a deflected flap. Using these design parameters, vortex generator blades were configured to the size indicated in Figure 7. Lin's range of effective micro vortex generator blade height is shown on the left of this figure. Note that the height of the individual blades is 0.2 inches which is approximately $5 \mathrm{~mm}(0.4 \delta)$. The blades were spaced in a co-rotating pattern one inch apart, and at 23degrees angle-of-attack to the flow direction. Figure 8 depicts the micro vortex generator array used for initial static flow control testing.

\section{Active Micro Vortex Generator Test Array}

The original project plan called for replacing the seven static vortex generators located at the center of the array with individually actuated, deployable blades for dynamic testing. When suitable piezoelectric actuators with the required displacement/frequency spectrum could not be located during early stages of the program, voice coil actuators were selected to drive the system. This substitution made it necessary to drive the entire seven-blade array with two actuators, instead of the originally planned individual blade actuation. This design change was made necessary because of off-the-shelf voice coil size availability. Figure 9 shows the deployable vortex generator array as configured for installation in the aerodynamic test model. The addition of the support beam and seven vortex generator blades reduced the deployment frequency capability of the system to a maximum of $90 \mathrm{~Hz}$; considerably less than the $240 \mathrm{~Hz}$ demonstrated by the individual amplifiers, but adequate to meet the reduced frequency bandwidth required for the planned separation control experiment.

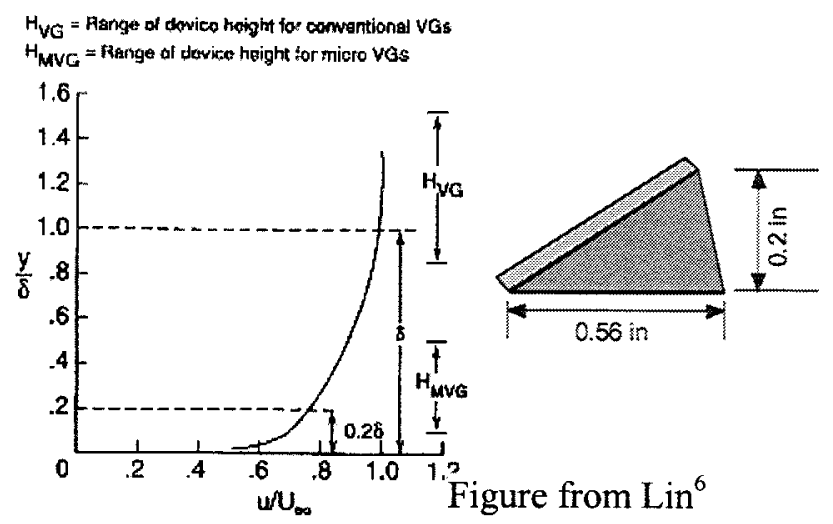

Figure 7: Vortex Generator Blade Design

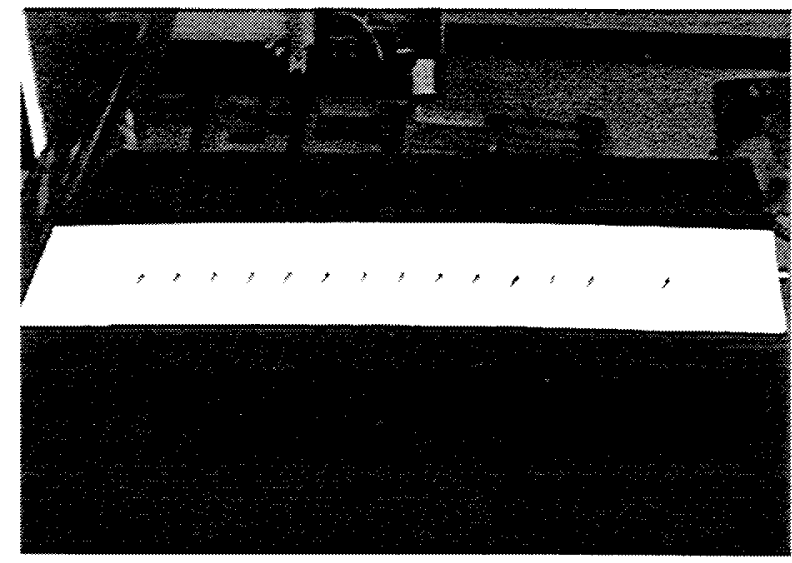

Figure 8: Installed Static Vortex Generator Test Array 


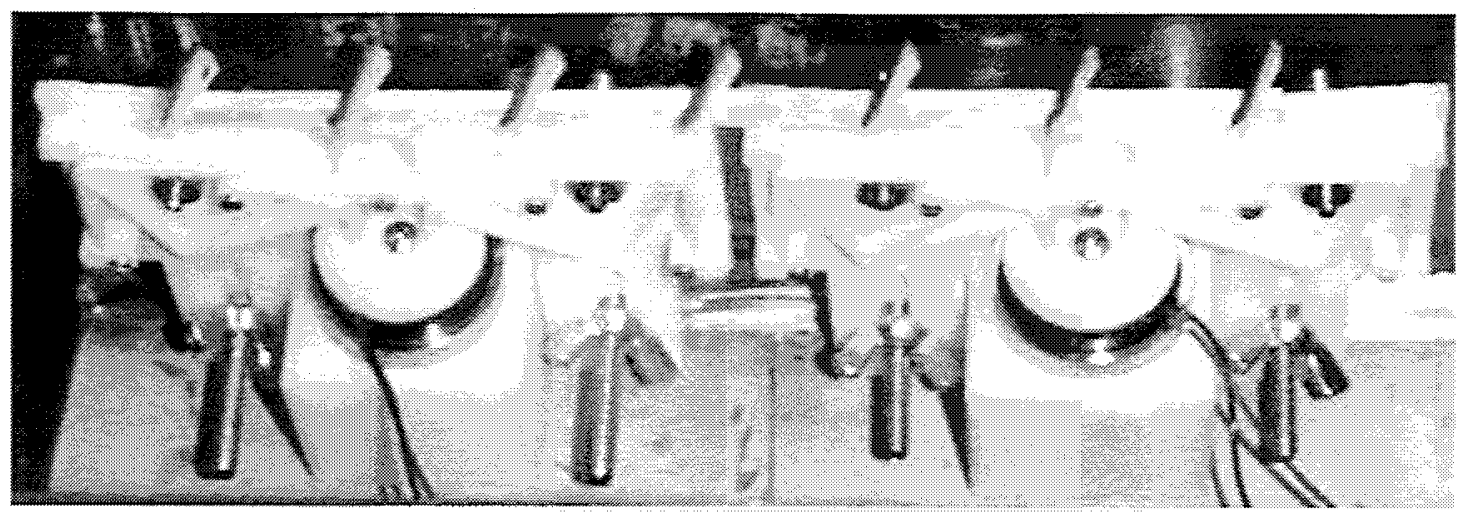

Figure 9: High Frequency, Deployable Micro Vortex Generator Test Hardware

\section{Flow Control Experiments}

\section{Wind Tunnel Model}

The configuration of the aerodynamic test article used during the program is shown in Figure 10. The model consists of a flat plate forward portion, with a rounded leading edge, mounting a trailing edge, variable angle flap. The flat plate portion of the test model contained a formed pocket located just forward of the trailing edge flap position. This pocket was sized to accept the HiMVG test hardware for the dynamic testing portion of the program. During the static vortex generator test phase, the

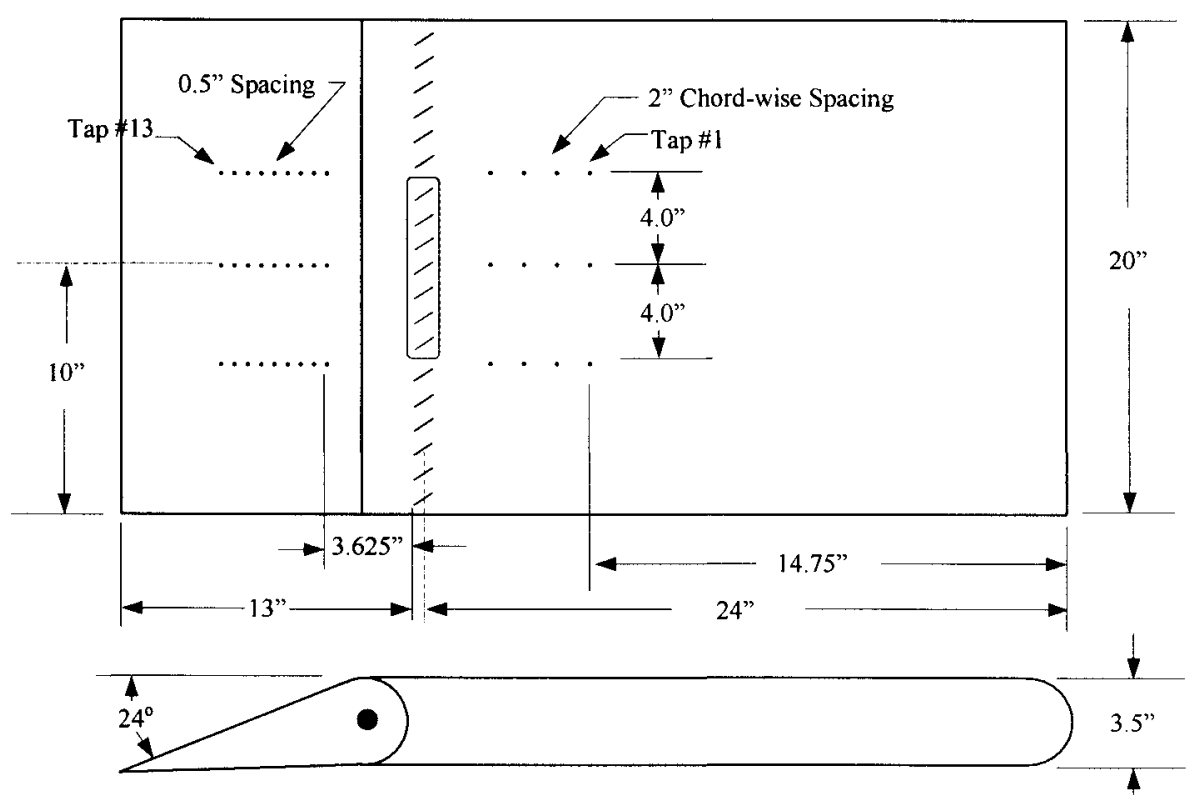

pocket was covered with a plate that mounted the static VG array.

Surface static pressure taps, a total of thirtynine, were installed in three chordwise rows as indicated. The box in the center of the array identifies the position of the deployable VG's. Figure 11 depicts the operating active micro vortex generator array integrated into the test model, with and without the cover plate installed. Power required to drive the actuators varied across the frequency spectrum, with the lowest power consumption, approximately five watts per channel, occurring close to the resonance frequency of $90 \mathrm{~Hz}$. The power draw increased to approximately 30 watts per actuator in the 40 to $50 \mathrm{~Hz}$ operating range. No attempt was made to design the system for minimum power operation as this would have required custom designed actuators whose cost were way beyond the funding level of this project. However, it should be noted that the power required to operate a similar system in a transonic flow environment does not increase, if proper attention is paid to amplifier-actuator design optimization.

Figure 10: Wind Tunnel Model and Pressure Instrumentation 


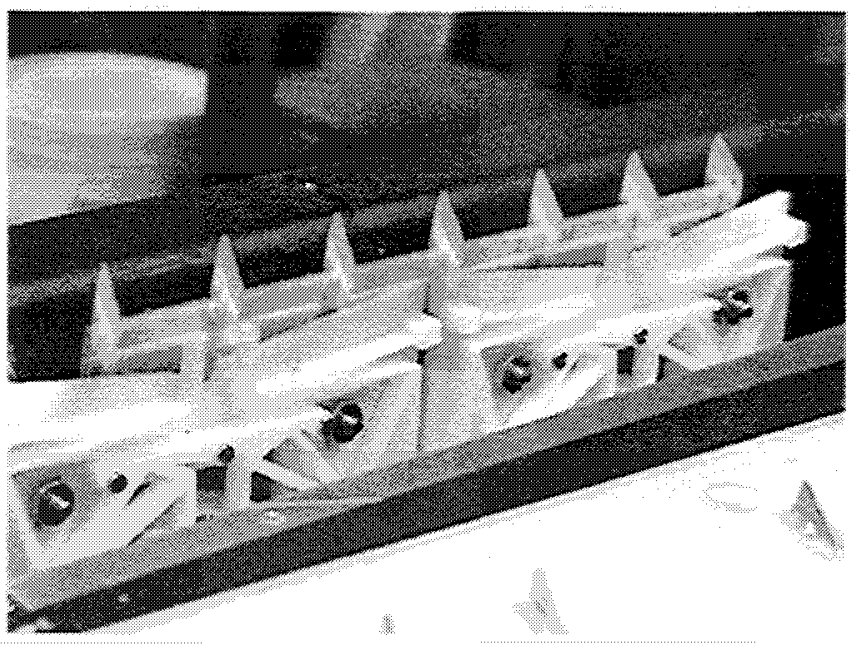

(a)

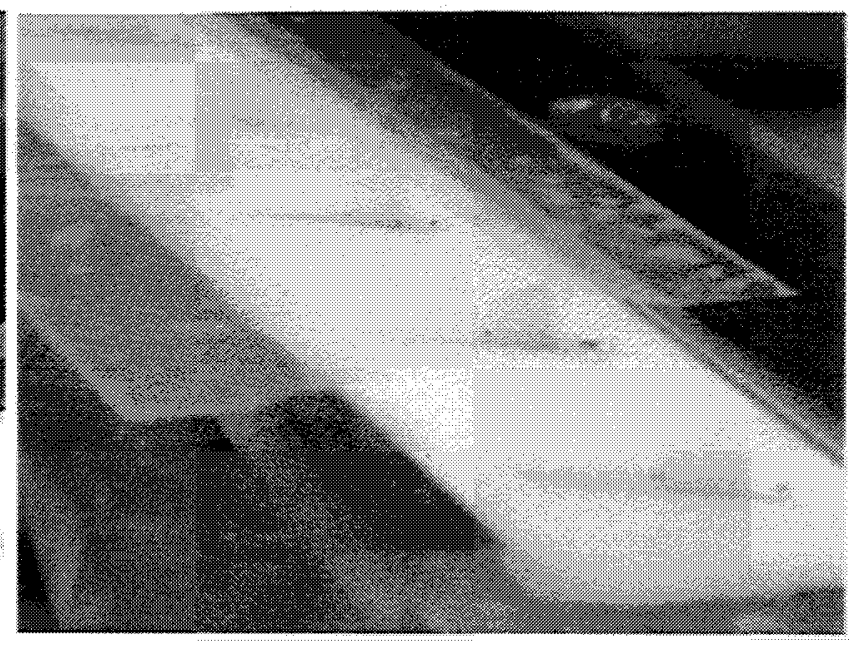

(b)

Figure 11: (a) Aerodynamic Test Model with HiMVG System Installed and Operating at $90 \mathrm{~Hz}$;

(b) Close-up of Vortex Blades Deploying at $90 \mathrm{~Hz}$ through Model Cover Plate

\section{Wind Tunnel Facility}

The University of Michigan 2' $\times 2$ ' subsonic wind tunnel, located in the Department of Aerospace Engineering, Research Building, was used for all the aerodynamic testing conducted during the program. The tunnel, shown in Figure 12, is an Eiffel type open return facility capable of variable test section velocities up to $80 \mathrm{ft} / \mathrm{sec}$. Removable panels in the wind tunnel ceiling provide easy access for model changes. Operation of the wind tunnel was controlled from a single console, which also incorporated all pressure instrumentation control functions.

\section{Instrumentation}

The primary instrumentation suite was a surface mounted static pressure array positioned as shown in Figure 10. The majority of the taps were spaced in $1 / 2$-inch chordwise increments on the trailing edge flap upper surface beginning as far forward on the flap as model construction details would permit. Installing pressure taps in the transition area near the flap leading edge would have provide a more detailed surface pressure map for determining turbulent boundary layer separation point as a function of flap deflection angle. However, including taps in this area would have complicated the flap deflection mechanism adding a significant increment to model fabrication cost. The pressure tap pattern used proved sufficient to delineate the upper surface separation characteristics for the test geometries investigated.

A multi-tube manometer board, which used water as the working fluid, was used to measure pressures. Individual static pressure taps were read sequentially, and recorded, using a Scanivalve system. Pressure readings were averaged over 500 milliseconds before being recorded. Each pressure was corrected, using measured test section static temperature, in the data reduction program.

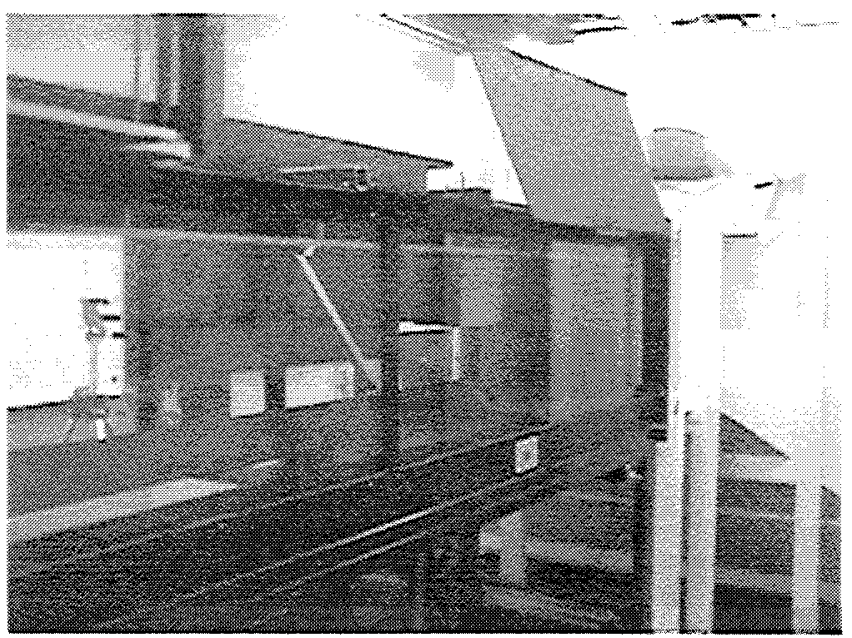

Figure 12: University of Michigan 2' $\times 2$ '

Subsonic Wind Tunnel 


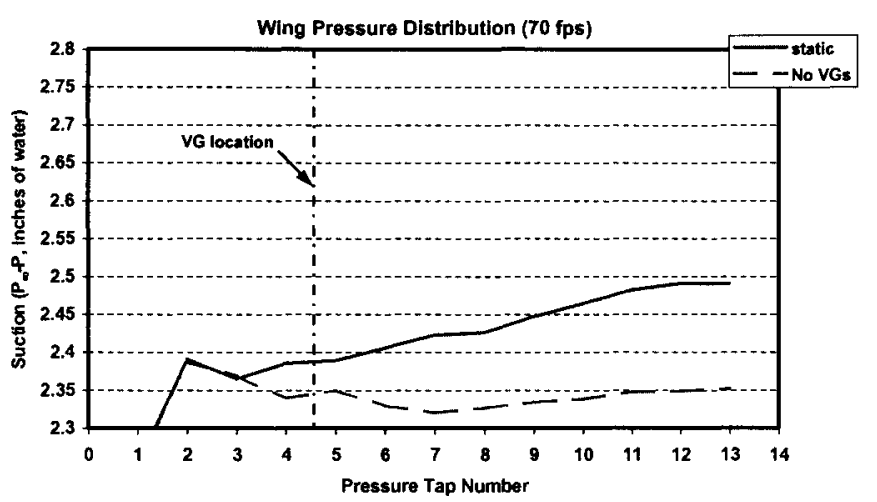

Figure 13: Aerodynamic Model Pressures, With and Without Static Vortex Generators Present

\section{Flow Control Results}

\section{$\underline{\text { Static }}$}

The focus of initial testing was to establish an appropriate adverse pressure gradient, separating flow field, on the flap upper surface. This was accomplished by deflecting the model trailing edge flap until the pressure instrumentation indicated boundary layer separation had occurred at the forward flap pressure station(s). The flat plate was mounted vertically in the wind tunnel, at zero angle-ofattack to the freestream, for all testing. No vortex generators were used during this test phase. Also, during this initial test phase, a boundary layer rake was used to confirm the presence of a turbulent boundary layer, approximately $1 / 2$-inch thick, at the position on the flat plate (see Figure 10) where the vortex generators would be located for testing.

A flap deflection angle of twenty-four degrees produced the pressure pattern shown in Figure 13. Note, the surface static pressure readings show no low-pressure region (no VG's case) on the flap upper surface, indicating the boundary layer has separated in the flat plate/flap transition area. Included on this plot is pressure data taken with the static vortex generator pattern (see Figure 8) in place. This data shows a decrease in pressure at the flap aft tap positions, but none at the forward positions. This indicates that the boundary layer is separating in the flat plate/flap transition area, but that the vortical flow field induced by the vortex generator array is producing an organized separated flow region above the flap that has a pronounced effect on the flap upper surface pressures. This same effect was recorded during subsequent testing using the dynamic vortex generator array position for static flow control measurement, i.e. the dynamic vortex generators were fixed in the extended, $5 \mathrm{~mm}$, position. The pressure data shown is for the centerline row of pressure taps only.

\section{Dynamic}

For this test phase, the static vortex generators at the center of the test array were replaced with the HiMVG test hardware depicted in Figure 9. The high frequency, deployable micro vortex generators were actuated, during the dynamic test phase, through a frequency range of 30$70 \mathrm{~Hz}$ using the electronic set-up shown in Figure 14. The dynamic flow control test series ran smoothly, although several adjustments had to be made to the vortex generator mounting beam mass to assure full stroke deployment, $5 \mathrm{~mm}$, was available at all test frequencies.

Two plots will be used to summarize the critical results of the dynamic flow control testing. These data are presented in Figure 15, which plots model upper surface suction in inches of water for the upper surface centerline static pressure taps, for the spectrum of frequencies tested. Two charts are presented, one for a test velocity of $55 \mathrm{ft} / \mathrm{sec}$, and another for a test velocity of $70 \mathrm{ft} / \mathrm{sec}$. By examining the data, one can readily see that operating the deployable vortex generators in a high frequency mode (deployment height $5 \mathrm{~mm}$ ) produced flow attachment on the forward portion of the flap

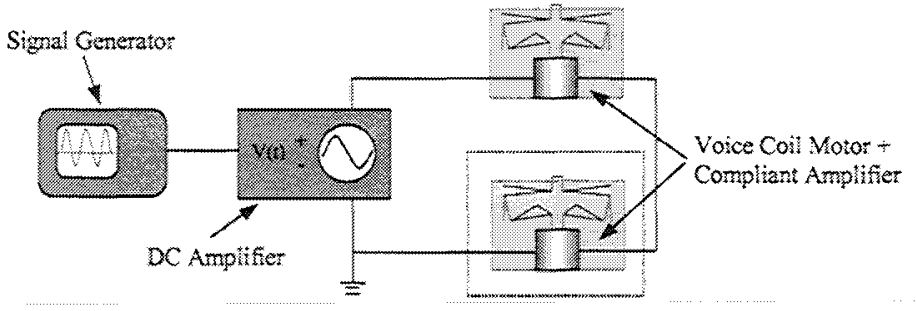

Figure 14: Voice-Coil Motor Wiring Diagram 
upper surface where none was present with the vortex generators statically deployed. Additionally, the oscillatory frequency spectrum for best flow attachment performance, judged by the negative pressure magnitude at tap locations 5 and 6 (the two forward most flap pressure locations), closely follows the subsonic flow control results of Wygnanski ${ }^{1}$. For example, using the reduced frequency definition of Ref. $1,\left(F^{+}=f \cdot X_{t e} / U\right)$, the $F^{+}$values where the HiMVG system performed best approach the value of $F^{+}=1$. The trend in deployment frequency for "best" flow control is consistent with the Reference 1 database; $70 \mathrm{~Hz}\left(F^{+}=1.08\right)$ producing the best results at the higher test velocity, and $60 \mathrm{~Hz}\left(F^{+}=1.18\right)$ performing better at the $55 \mathrm{ft} / \mathrm{sec}$ test condition.

Additional pressure taps in the vicinity of the flat plate/flap transition area would have been helpful in quantifying more accurately the
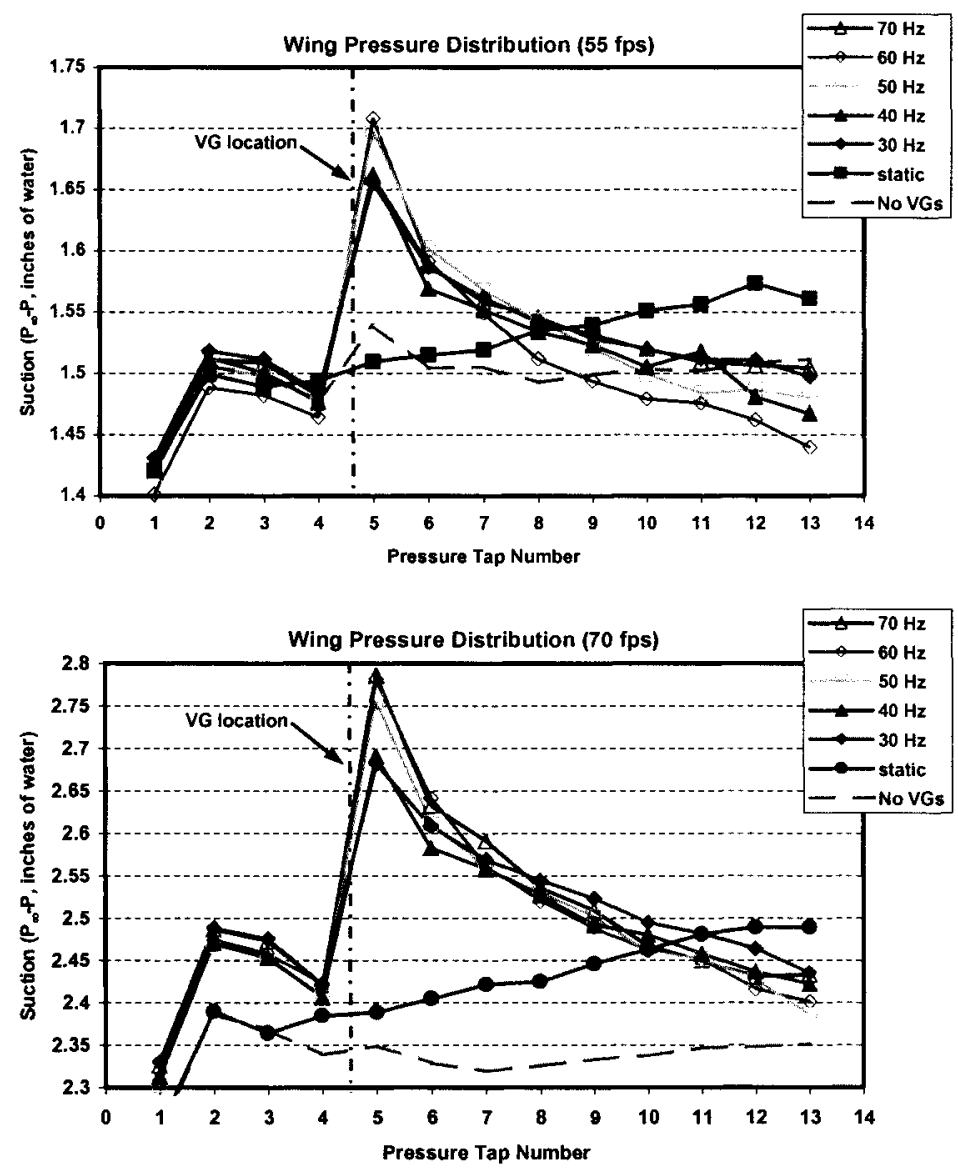

Figure 15: HiMVG Dynamic Test Results optimum deployment frequency for turbulent boundary layer separation control. Testing deployment frequencies in $5 \mathrm{~Hz}$ increments, and acquiring pressure data at additional tunnel speeds would also have been helpful in this area. However, measured results with the available instrumentation proved sufficient to quantify the efficacy of the mechanical flow control device tested. The data taken were repeatable, and in the bottom line, produced turbulent boundary layer separation results comparable to the best oscillatory pneumatic systems.

\section{Conclusions}

This initial development of a mechanical, high frequency active flow control device accomplished the following items related to amplifier - actuator design and fabrication, and active flow control demonstration.

\section{Displacement Amplification Compliant} Structure

- The successful design and fabrication of a compliant structure with a displacement amplification of 20:1.

- Integrated design and demonstration of an amplifier - actuator system that achieved an output stroke of $5 \mathrm{~mm}$ while operating in the frequency range between 0 to $240 \mathrm{~Hz}$.

- Developed and demonstrated a dual amplifier-actuator system that drives seven deployable vortex generator blades in unison, and operates in the frequency range between 0 and $90 \mathrm{~Hz}$.

- Conceptually designed a compact second-generation HiMVG device (described next Section).

\section{Flow Control}

- The micro vortex generator geometries, developed and demonstrated by $\operatorname{Lin}^{6}$ in the static flow control environment, work well in a dynamic flow control system. 


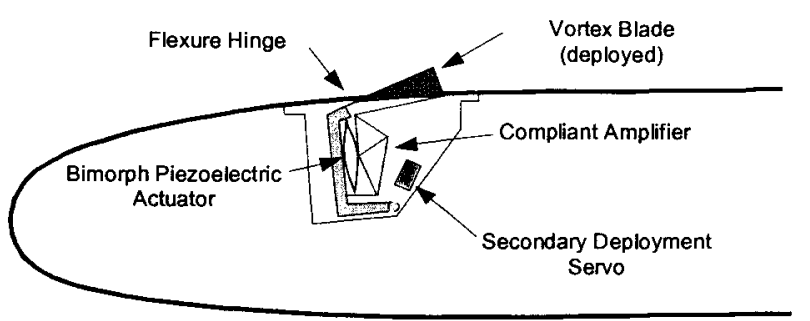

(a) Vortex Blade Deployed

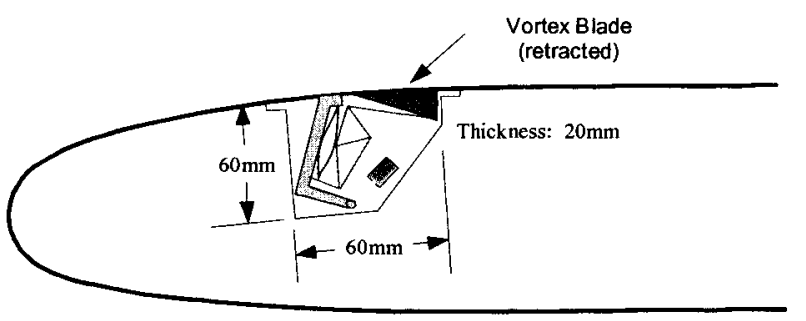

(b) Vortex Blade Retracted

Figure 16: Concept Sketch of Second Generation High Frequency Micro Vortex Generator Device

- The oscillatory flow field produced by a deployable vortex generator array is an effective means of energizing a separating turbulent boundary layer.

- The HiMVG system when operating at a reduced frequency of $F^{+} \sim 1$ produces separation control results, in a subsonic flow environment, comparable to the best oscillatory pneumatic systems.

\section{Future Research Directions}

The next step in the development of a versatile, mechanical HiMVG flow controller must address system integration issues. A secondgeneration design developed in the latter stages of the current program is illustrated in Figure 16. This design attacks shortcomings present in the demonstrated system, and opens up additional flow control applications where size and power are first priority design parameters.

First the vortex generator blade(s) is flush with the aerodynamic surface when retracted, eliminating the surface pockets present with the current design. An indexing actuator is used to deploy the blade to an optimum extension position around which the blade is oscillated. During the course of the current experimental program, it was determined that oscillating the blade through the $2 \mathrm{~mm}$ of boundary layer adjacent to the surface had no effect on downstream vortex strength. For maximum effectiveness, the blade should be extended to the position of maximum vorticity production and oscillated around that position at the critical frequency. However, if the device is used for dynamic stall control, an area of high current interest in this program's sponsoring agency, different flow mechanisms are involved, and the indexing position around which the vortex generator oscillates may need to move as the airfoil is in the pitch-up process.

A second, and critical element of the secondgeneration design is the use of compact, energyefficient, electrically driven actuators to drive the oscillation. Devices, such as, bimorph piezoelectric actuators from Piezo Systems Inc. have been identified that will provide the necessary deflection versus frequency performance needed for second-generation HiMVG device applications. Piezoelectric actuation is necessary to configure the compact system conceptualized in the in Figure 16. Piezoelectric devices were initially considered for actuator use in the current program, but were replaced by voice coils when the initial testing of several piezoelectric samples failed to produce the deflection/frequency characteristics required.

A research opportunity exists to explore the application of HiMVG devices for aircraft dynamic stall control. In the past, much has been written about flow control for enhanced maneuverability, and extended operating times in the region beyond aircraft static maximum lift. The second generation HiMVG device, properly developed, would bring a new active flow control concept to this arena, which will work effectively in a transonic flow environment, and only requires a small amount of electrical power for operation. 


\section{Acknowledgement}

The authors would like to acknowledge the funding support provided for this project by Dr. Steven Walker, Air Force Office of Scientific Research (AFOSR). His support for this program was a key factor in bringing compliant structures technology into the active flow control research arena.

\section{References}

${ }^{1}$ Katz, Y., Nishri, B., and Wygnanski, I, "The Delay of Turbulent Boundary Layer Separation by Oscillatory Active Flow Control," AIAA Paper 89-0975, 1989.

${ }^{2}$ McManus, K., et al., "Pulsed Vortex Generator Jets for Active Flow Control," AFRL-VA-WP-TR-1998-3028, Nov. 1997.

3 Seifert, A., and Pack, L. G., "Oscillatory Control of Separation at High Reynolds Numbers," AIAA Paper 98-0214, $36^{\text {th }}$ Aerospace Sciences Meeting, Reno, NV, January 1998.

${ }^{4}$ Magill, J. C., and McManus, K., "Control of Dynamic Stall using Pulsed Vortex Generator Jets," AIAA Paper 98-0675, $36^{\text {th }}$ Aerospace Sciences Meeting, Reno, NV, January 1998.

5 Tilmann, C. P., "Enhancement of Transonic Airfoil Performance Using Pulsed Jets for Separation Control," AIAA Paper 2001-0731, $39^{\text {th }}$ Aerospace Sciences Meeting, Reno, NV, January 2001.

6 Lin, J. C., "Control of Turbulent Boundary Layer Separation Using Micro-Vortex Generators," AIAA Paper 99-3404, 30 ${ }^{\text {th }}$ AIAA Fluid Dynamics Conference, June 28 - July 1, 1999.

${ }^{7}$ Lisy, F., and Schmidt, R., "Large Throw, Imbedded Microactuators for Drag Reduction," USAF, Air Force Research Laboratory, Contract F33615-95-C-3003, December 1995.

8 Schubauer, G. B., and Spangenberg, W. G., "Forced Mixing in Boundary Layers," Journal of Fluid Mechanics, No.8, Part I, 1960.

${ }^{9}$ Wygnanski, I., "Some new observations affecting the control of separation by periodic excitation," AIAA Paper 2000-2314, 2000.

${ }^{10}$ Osborn, R., Hetrick, J., Kota, S., Geister, D., Lee, M., and Joo, J., "High Frequency Vortex Generators for Active Flow Control using Compliant Systems," $A F O S R T R$, dated May 2001, to be published. 